\title{
Dopamine Depletion of the Prefrontal Cortex Induces Dendritic Spine Loss: Reversal by Atypical Antipsychotic Drug Treatment
}

\author{
Hui-Dong Wang*,' and Ariel Y Deutch' \\ 'Departments of Psychiatry and Pharmacology, Vanderbilt University Medical Center, Nashville, TN, USA
}

\begin{abstract}
Dystrophic changes in dendrites of cortical neurons are present in several neuro-psychiatric disorders, including schizophrenia. The mechanisms that account for dendritic changes in the prefrontal cortex (PFC) in schizophrenia are unclear. Cognitive deficits in schizophrenia have been linked to compromised cortical dopamine function, and the density of the PFC dopamine innervation is decreased in schizophrenia. We determined if 6-hydroxydopamine lesions of the ventral tegmental area that disrupt the PFC dopamine innervation cause dystrophic changes in cortical neurons. Three weeks post-operatively we observed a marked decrease in basal dendritic length and spine density of layer $\vee$ pyramidal cells in the prelimbic cortex; no change was seen in neurons of the motor cortex. We then examined rats in which the PFC dopamine innervation was lesioned and 3 weeks later were started on chronic treatment with an atypical (olanzapine) or typical (haloperidol) antipsychotic drug. Olanzapine but not haloperidol reversed lesion-induced changes in PFC pyramidal cell dendrites. These data suggest that dopamine regulates dendritic structure in PFC neurons. Moreover, the findings are consistent with a decrease in cortical dopaminergic tone contributing to the pathological changes in the cortex of schizophrenia, and suggest that the progressive cortical loss in schizophrenia may be slowed or reversed by treatment with atypical antipsychotic drugs. Neuropsychopharmacology (2008) 33, 1276- 1286; doi:I0.1038/sj.npp. I30I52I; published online 8 August 2007
\end{abstract}

Keywords: dendrite; haloperidol; motor cortex; olanzapine; pyramidal cell; schizophrenia

\section{INTRODUCTION}

A generation ago, in a provocatively titled paper, Crick (1982) posed the question 'Do spines twitch?'. Over the ensuing years it has become clear that dendritic spines indeed twitch, and are not static processes but instead dynamic processes that are highly regulated both in health and disease (Fiala et al, 2002; Blanpied and Ehlers, 2004; Zaja-Milatovic et al, 2005; Hao et al, 2006). Among the disorders marked by dystrophic changes of dendrites is schizophrenia, in which the pyramidal cells of the prefrontal cortex (PFC) are prominently affected.

The search for a structural basis of schizophrenia has been ongoing for a century, but only over the past decade has the application of quantitative anatomical methods to postmortem material and in vivo imaging data consistently yielded evidence of structural brain changes (Harrison, 1999; Selemon and Goldman-Rakic, 1999; Lewis and Lieberman, 2000; Antonova et al, 2004). Although morphological changes are present in several brain regions,

* Correspondence: Dr H-D Wang, Departments of Psychiatry and Pharmacology, Vanderbilt University Medical Center, 1601 23rd Ave South, Suite 313, Nashville, TN 37212, USA, Tel: + I 615327 7080, Fax: + I 615322 1901, E-mail: huidong.wang@vanderbilt.edu

Received 30 May 2007; revised and accepted 5 July 2007 particular attention has focused on the PFC, dysfunction of which is associated with certain cognitive deficits in schizophrenia (Park and Holzman, 1992; Goldman-Rakic, 1996; Meltzer et al, 1999; Gur et al, 2000; Antonova et al, 2004). Recent studies have reported cortical volume decreases in schizophrenia, including in first-episode patients (Gur et al, 2000; Cahn et al, 2002; Lieberman et al, 2005a). However, most postmortem studies have not found a significant decrease in the overall number of neurons (Selemon et al, 1999; Thune et al, 2001), although oligodendrocyte number appears to change (Hof et al, 2003). A normal complement of neurons in the face of a decrease in volume suggests a reduction in neuropil (Selemon and Goldman-Rakic, 1999), which may reflect a decreased density of presynaptic elements or dendrites; alternatively, soma size may be reduced. To varying degrees all three of these factors probably contribute to cortical volume loss in schizophrenia (Harrison, 1999; Selemon and Goldman-Rakic, 1999; Glantz and Lewis, 2000; Mirnics et al, 2001; Halim et al, 2003; Pierri et al, 2003).

Several groups have reported dystrophic changes in frontal cortical pyramidal cell (PC) dendrites in schizophrenia, including decreases in dendritic length, branching, and spine density (Garey et al, 1998; Glantz and Lewis, 2000; Kalus et al, 2000; Broadbelt et al, 2002; Black et al, 2004; Kolluri et al, 2005). These dendritic changes have been 
observed in several frontal cortical regions (Brodmann's areas $10,11,32$, and 46 ) but not in the primary visual cortex (Glantz and Lewis, 2000). The mechanisms that account for these dendritic changes are poorly understood (Hill et al, 2006).

Prefrontal cortical pyramidal cells that receive dopamine afferents often display a synaptic architecture that involves the dopamine axon synapsing onto the neck of a dendritic spine and an axon of unknown origin forming an asymmetric synapse with the head of that spine (Sesack et al, 2003). A similar triadic arrangement is seen in medium spiny neurons of the striatum (Freund et al, 1984), where dopamine depletion decreases dendritic length and spine density of the medium spiny neurons (Ingham et al, 1989; Zaja-Milatovic et al, 2005). In vivo imaging and behavioral studies strongly suggest that PFC dopamine function is compromised in schizophrenia (Goldman-Rakic and Selemon, 1997; Arnsten, 2004; Gibbs and D'Esposito, 2005) and Akil et al (1999) have provided morphological evidence of a decreased density of the dopaminergic innervation of the PFC.

The question of whether the pathological changes in the cortex in schizophrenia are fixed or can be altered by appropriate treatment is unresolved. Atypical antipsychotic drugs (APDs) have been suggested to be superior to typical APDs in treating cognitive deficits in schizophrenia (Meltzer et al, 1999; Bilder et al, 2002; Volavka et al, 2002; Keefe et al, 2004), although recent data question that conclusion (Lieberman et al, 2005a). In addition, a study of first-episode schizophrenic patients treated with the atypical APD olanzapine, but not with the typical APD haloperidol, found that the atypical APD prevented progressive cortical volume loss over the ensuing 2 years and resulted in significant improvement in cognitive function (Lieberman et al, 2005b).

These observations suggest that the loss of cortical dopamine, which is thought to be associated with cognitive deficits (Davis et al, 1991; Knable and Weinberger, 1997; Meltzer et al, 1999; Goldman-Rakic et al, 2004), may contribute to dystrophic changes in PC dendrites. We therefore determined if dopamine depletion of the PFC leads to dendritic spine loss on frontal cortical PC dendrites, and then assessed if treatment with typical or atypical APDs attenuates any effects of cortical dopamine depletion on pyramidal cell dendrites.

\section{MATERIALS AND METHODS}

Adult male Sprague-Dawley rats (Harlan; Indianapolis, IN, USA) were group-housed with food and water ad libitum. All experiments were performed in accordance with the Guide for the Care and Use of Laboratory Animals as promulgated by the National Institutes of Health.

\section{Experimental Design and Treatments}

Animals received bilateral 6-hydroxydopamine (6-OHDA) lesions of the ventral tegmental area (VTA), as described previously (Deutch et al, 1990); vehicle-injected animals served as controls. We injected the catecholamine neurotoxin into the VTA rather than directly into the PFC because of the likelihood that intracortical injections would cause non-specific effects on the structure of local neurons. Three weeks after the VTA lesions, animals were perfused with $4 \%$ paraformaldehyde and $0.05 \%$ glutaraldehyde, and the PFC was processed using a modified Golgi-Cox method in which the development step was shortened; sections through the midbrain were immunohistochemically processed to reveal tyrosine hydroxylase-immunoreactive (-ir) dopamine neurons in the midbrain. Because of the time and labor involved in reconstructing neurons, and because the aldehyde perfusion precluded obtaining biochemical measures of the extent of dopamine depletion in the same animals in which Golgi impregnation was performed, the midbrain sections from each animal were screened for the extent of the VTA lesion by a person unaware of the treatment condition of the animals. In those cases in which the lesion was subjectively assessed to involve less than $<50 \%$ of the dopamine neurons, the animal was excluded from subsequent analyses. Final group sizes after eliminating the animals with incomplete lesions were six shamlesioned rats and seven VTA-lesioned rats.

To arrive at some idea of the extent of dopamine depletion in the PFC, separate groups of animals from those used for the anatomical studies were given 6-OHDA VTA lesions and 3 weeks later killed. The PFC was dissected (Deutch et al, 1985) and concentrations of dopamine and norepinephrine in these samples were assayed by HPLC-EC (Deutch and Cameron, 1992). Data were analyzed by $t$-tests with experiment-wise $\alpha$ set at 0.025 to account for comparing dopamine and norepinephrine concentrations.

In a second experiment aimed at determining if APD treatment modifies the effects of dopamine denervation on PC morphology, animals received VTA or sham lesions. Three weeks after the lesions were made rats were randomly assigned to receive haloperidol (target dose $2.0 \mathrm{mg} / \mathrm{kg} /$ day, p.o.), olanzapine (target dose $7.5 \mathrm{mg} / \mathrm{kg} /$ day), or vehicle (water to which $0.75 \%$ sucrose was added). The achieved average daily dose of the APDs was $1.84 \mathrm{mg} / \mathrm{kg} / \mathrm{day}$ haloperidol and $6.59 \mathrm{mg} / \mathrm{kg} /$ day olanzapine. Administration of haloperidol and olanzapine in the drinking water at these dose levels result in stable plasma drug levels and brain occupancy of $\mathrm{D}_{2}$ dopamine receptors comparable to that seen in patients treated with these drugs (Terry et al, 2005; Perez-Costas et al, 2005). Animals were maintained on the APDs for 3 more weeks, killed, and the frontal cortex processed for Golgi impregnation. Thus, in the second experiment there were six groups of animals: sham-lesioned rats that received vehicle, haloperidol, or olanzapine, and 6-OHDA-lesioned rats treated with vehicle, haloperidol, or olanzapine. Final group sizes ranged from 5 to 8 , varying due to loss of animals in various treatment groups because of incomplete lesions or death.

\section{Neuronal Reconstruction and Data Analysis}

The medial PFC of the rat consists of several cytoarchitectonically distinct areas that have different projections. Because the prelimbic cortex of the rat receives convergent inputs from the mediodorsal thalamus, basolateral amygdala, and ventral tegmental area and thus resembles the dorsolateral PFC of primates, and because behavioral studies suggest that the prelimbic cortex subserves working 
memory tasks (Ragozzino et al, 2002; Dalley et al, 2004), we analyzed pyramidal cells in the prelimbic cortex (area 32; see Krettek and Price, 1977). We focused our efforts on layer $\mathrm{V}$ neurons because the dopamine innervation of the rat is most dense in layer $\mathrm{V}$ and drops off relatively sharply at layer III (van Eden et al, 1987).

Golgi-impregnated PCs in the prelimbic cortex were reconstructed from $150-\mu \mathrm{m}$-thick sections by persons unaware of the treatment condition of the animals. At least five pyramidal neurons from each animal were chosen for reconstruction based on the following characteristic: (1) the cells were in layer $\mathrm{V}$ of the prelimbic cortex in the medial PFC; (2) the neurons had a pyramidal morphology that grossly appeared to be well-filled and evenly impregnated under $\times 10$ objective examination; (3) at least three basilar dendritic shafts emanated from the soma; (4) soma and dendrites were not obscured by other structures. The image of the PFC was acquired by a digital camera coupled to a computer running the cell reconstruction software Neurolucida (MicroBrightField Inc., Williston, VT). A line was drawn from the pial surface to the white matter at a point midway between the dorsal and ventral borders of the prelimbic cortex. This line was followed from the pial surface until a Golgi-impregnated layer V pyramidal cell (range: $614 \pm 21$ to $1063 \pm 20 \mu \mathrm{m}$ from the pial surface) was encountered and that appeared under a $\times 10$ objective to be completely impregnated. After marking the position of this initial neuron in the PFC, the cell was reconstructed, and then adjacent impregnated neurons both dorsal and ventral to the first (index) neuron were reconstructed, under $\times 126$ objective magnification (using a high NA $\times 63$ objective, the magnification of which was doubled digitally using the image capture program). The average depth of the reconstructed neurons from the pial surface was $808 \pm 37 \mu \mathrm{m}$. Dendrites were traced and any sudden truncations due to transection or artefact were noted . Pyramidal cell volume was estimated using the contour tracing function of the Neurolucida program, sequentially determining the area of the pyramidal cell at $5 \mu \mathrm{m}$ steps from the largest diameter of the soma and then merging the data. A total of 148 neurons was reconstructed in the prelimbic and motor cortex in experiment 1, and 202 neurons were reconstructed and analyzed in experiment 2.

In the first experiment examining the effects of VTA lesions on PFC pyramidal cell dendrites, we also determined if the dendrites of layer V PCs in the primary M1 motor cortex were impacted by the lesions. We elected to analyze the motor cortex because it is located in the same coronal sections as the PFC, but does not receive a dopamine innervation (Van Eden et al, 1987). Thus, the motor cortex serves as an excellent control site in which to test the hypothesis that the PFC dopamine innervation is necessary for pyramidal cell dendritic spine maintenance.

After neurons were reconstructed and the average values for the dendritic parameters were calculated, the code for the slides was broken and group differences in soma area, total basal dendritic length, total basal dendritic spine density, spine density as a function of distance from the soma, and concentric $(20 \mu \mathrm{m})$ ring intersections by dendrites (Sholl analysis) were determined. The apical dendrites of layer V PCs were usually transected as they coursed to the superficial layers, and we were therefore not able to obtain full data on the apical dendritic tree. However, we were able to reliably reconstruct the proximal portion of the apical dendrites of layer V PCs, and therefore measured apical dendritic spine density at a distance of $80-100 \mu \mathrm{m}$ from the soma.

In the first experiment, $t$-tests were used to assess significant changes in basal and apical dendrite spine density, dendritic length, and soma size, with the $\alpha$ level set at 0.01 to control for multiple comparisons. Data from the second experiment, which examined the effects of APD treatment of VTA-lesioned rats, were analyzed by means of two-way ANOVAs, followed by Bonferroni $t$-tests when indicated. In all cases the mean of the various dendritic parameters of the neurons in a given animal were used in the statistical analyses, that is, the statistical analysis was performed on the data of subjects. A power analysis was performed using the data from the first experiment. To achieve $83 \%$ power at a Type I error rate of 0.05 , we found that 5 cells/animal were required to detect changes in total basal dendritic length; 5 cells/animal yielded $97 \%$ power for dendritic spine density.

\section{RESULTS}

\section{Lesion-Induced Changes in PFC Catecholamine Concentrations}

6-hydroxydopamine VTA lesions resulted in marked loss of dopamine neurons in the VTA, with some sparing of the midline dopamine neurons in the interfascicular and rostral and caudal linear nuclei (see Figure 1); variable loss of substantia nigra and retrorubral dopamine neurons was also seen. Biochemical measurements revealed that dopamine concentrations in the PFC decreased to $23 \%$ of control values $\left(t_{10}=8.70, p<0.001\right)$; control levels of dopamine were $0.91 \pm 0.19 \mathrm{ng} / \mathrm{mg}$ protein.

Norepinephrine concentrations did not differ significantly between control and VTA-lesioned rats $\left(t_{10}=1.98\right.$, NS).

\section{VTA Lesions and PC Dendritic Morphology}

In the first experiment on the effects of cortical dopamine denervation on PC morphology, we found that 6-OHDA lesions sharply decreased overall basal dendritic length and spine density of layer V PCs (see Table 1). Apical dendritic spine density did not change significantly, although a trend toward a decrease $(p=0.055)$ was seen. Average soma

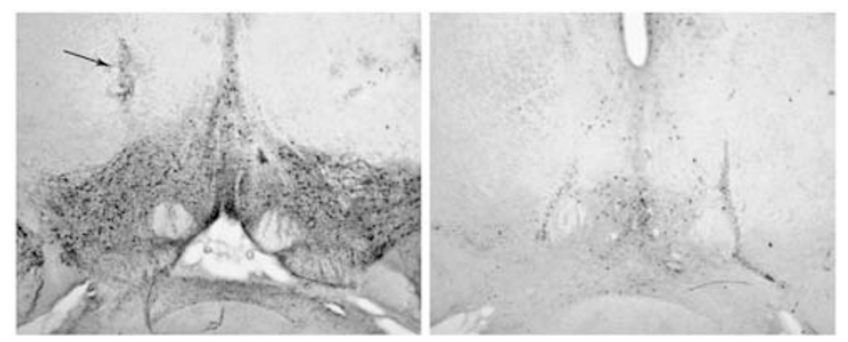

Figure I 6-Hydroxydopamine lesions of the VTA resulted in a marked loss of tyrosine hydroxylase-immunoreactive neurons (right panel) relative to the vehicle-injected control (left panel). There was some sparing of midline DA neurons. The cannula tracts can be seen bilaterally (arrows). 
Table I Effects of VTA 6-OHDA Lesions on Dendritic Parameters in the Prefrontal and Motor Cortex

\begin{tabular}{|c|c|c|c|c|}
\hline & \multicolumn{2}{|c|}{ Prefrontal cortex } & \multicolumn{2}{|c|}{ Motor cortex } \\
\hline & Sham & Lesion & Sham & Lesion \\
\hline Overall basal dendritic spine density (spines/ I $0 \mu \mathrm{m}$ dendritic length) & $3.27 \pm 0.28$ & $1.94 \pm 0.06 *$ & $3.73 \pm 0.06$ & $3.51 \pm 0.18$ \\
\hline Apical dendritic spine density (spines/ $10 \mu \mathrm{m}$ dendritic length) & $2.78 \pm 0.45$ & $1.72 \pm 0.25$ & $3.89 \pm 0.56$ & $3.81 \pm 0.32$ \\
\hline
\end{tabular}

$* p \leqslant 0.001$.

Table 2 Volume of Layer $\vee$ Pyramidal Neurons in Sham- and VTA-Lesioned Rats Treated with APDs

\begin{tabular}{lcc}
\hline & \multicolumn{1}{c}{ Sham } & Lesion \\
\hline Vehicle & $5094.1 \pm 511.9(5)$ & $5183.9 \pm 824.9(5)$ \\
Haloperidol & $4549.2 \pm 370.5(5)$ & $4296.1 \pm 263.5(8)$ \\
Olanzapine & $4786.3 \pm 295.3(6)$ & $4466.7 \pm 249.9(7)$ \\
\hline
\end{tabular}

Values represent volume of pyramidal cells in $\mu \mathrm{m}^{3}$.

volume of the neurons did not differ between the control and 6-OHDA-lesioned groups. In sharp contrast to the effects of VTA lesions on PFC pyramidal cells, we did not observe any effects of the lesion on the basal or apical dendrites of layer V PCs in the M1 motor cortex.

\section{Effects of APD Treatment on Pyramidal Cell Dendrites}

In the second experiment we determined if treatment with APDs modified dopamine depletion-induced changes in PC dendrites. Again, VTA lesions caused dendritic changes in PFC pyramidal cells. In addition, treatment with olanzapine, but not haloperidol, reversed these dendritic changes. There were no significant differences in the volume of layer $\mathrm{V}$ somata across the different groups (see Table 2).

Analysis of variance uncovered a significant effect of PFC dopamine depletion on basal dendritic length $\left(\mathrm{F}_{5,30}=4.37\right.$, $p=0.004$ ). Post hoc Bonferroni tests revealed that the total length of basal dendrites from VTA-lesioned vehicle-treated rats was significantly decreased relative to sham-operated vehicle-treated controls (see Figures 2, 3 and 6), consistent with the data from the first experiment. Neither haloperidol nor olanzapine treatment of sham-operated rats changed basal dendritic length. However, administration of olanzapine but not haloperidol to VTA-lesioned rats reversed the decrease in dendritic length to levels that did not significantly differ from either sham-lesioned vehicletreated or sham-lesioned olanzapine-treated rats (Figure 2). The coefficients of variation across the six groups did not significantly differ $\left(\mathrm{F}_{5,30}=1.643, \mathrm{NS}\right)$, suggesting that there was no systematic bias across groups other than treatment conditions. Rats with cortical dopamine denervation that received vehicle also showed a decrease in overall basal dendritic spine density relative to sham-operated, vehicletreated animals $\left(\mathrm{F}_{5,30}=19.3, p<0.0001\right)$, again confirming the results of the initial experiment. Treatment with olanzapine but not haloperidol reversed the dendritic spine loss seen in the animals with cortical dopamine depletion
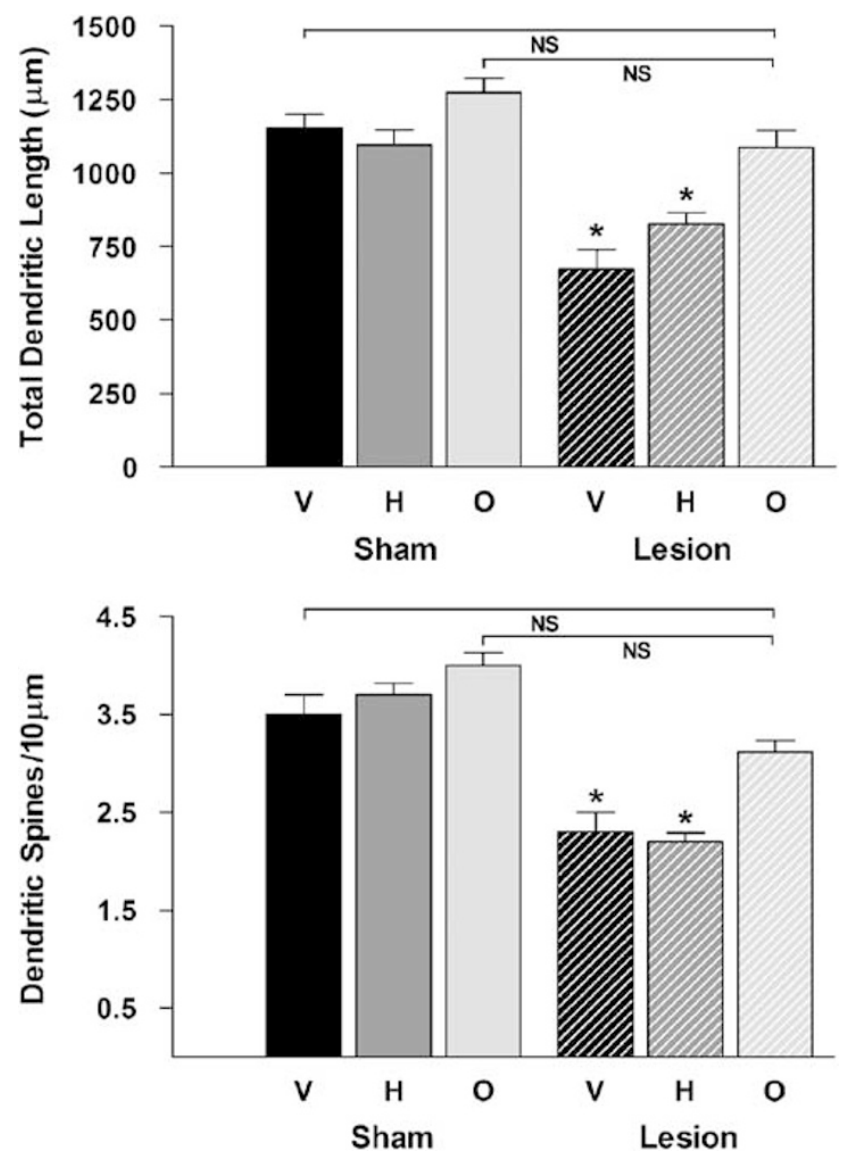

Figure 2 Effects of chronic treatment with haloperidol $(H)$ or olanzapine (O) on total basal dendritic length (top panel) and dendritic spine density (bottom panel) in rats with cortical DA denervation. 6-OHDA lesioned rats that were treated with vehicle $(V)$ had a marked decrease in basal dendritic length and spine density relative to sham-lesioned vehicle-injected animals. Olanzapine but not haloperidol restored basal dendritic length and spine density to levels comparable to those in sham-lesioned vehicletreated animals. $* p \leqslant 0.00$ I relative to sham-lesioned vehicle-treated group; NS, not significant.

(see Figures 2 and 3). A two-way repeated measures ANOVA examining spine density as a function of distance from the soma (see Figure 4) revealed significant treatment $\left(\mathrm{F}_{5,178}=31.0, \quad p<0.0001\right)$ and distance $\left(\mathrm{F}_{5,178}=154.3\right.$, $p<0.0001)$ effects, but no interaction. While the magnitude of lesion-induced decreases in spine density appeared subjectively to be more prominent on the distal dendritic tree (see Figure 4), no statistically significant effect was uncovered. Subsequent analyses found that lesion-induced decrease in spine density were reversed by olanzapine but 
Basal
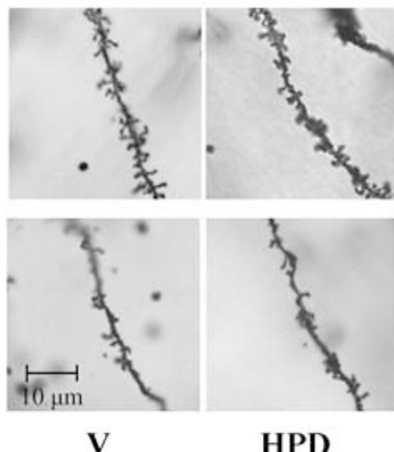

$\mathrm{V}$
HPD
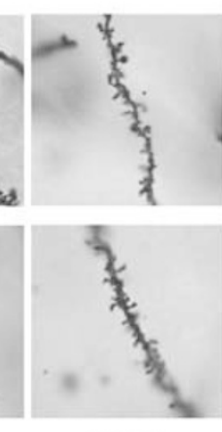

OLZ

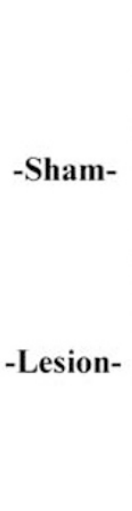

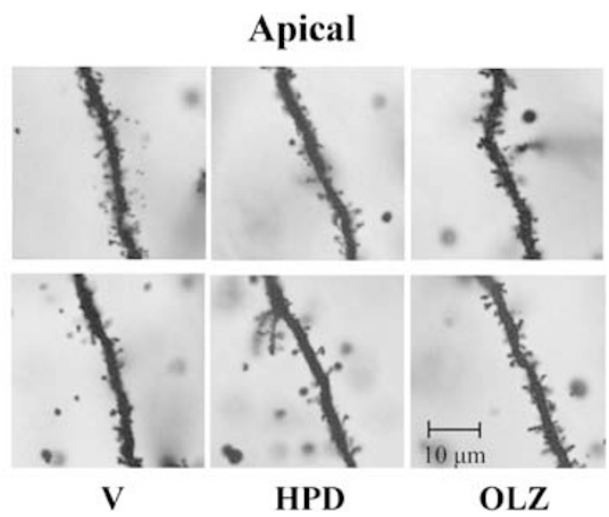

Figure 3 Photomicrographs of representative basal (left) and the main shaft of apical (right) dendritic segments in the various treatment groups of the second experiment. The images were obtained from dendritic segments located 60-100 $\mu \mathrm{m}$ distal to the soma. Scale bar $=10 \mu \mathrm{m}$.

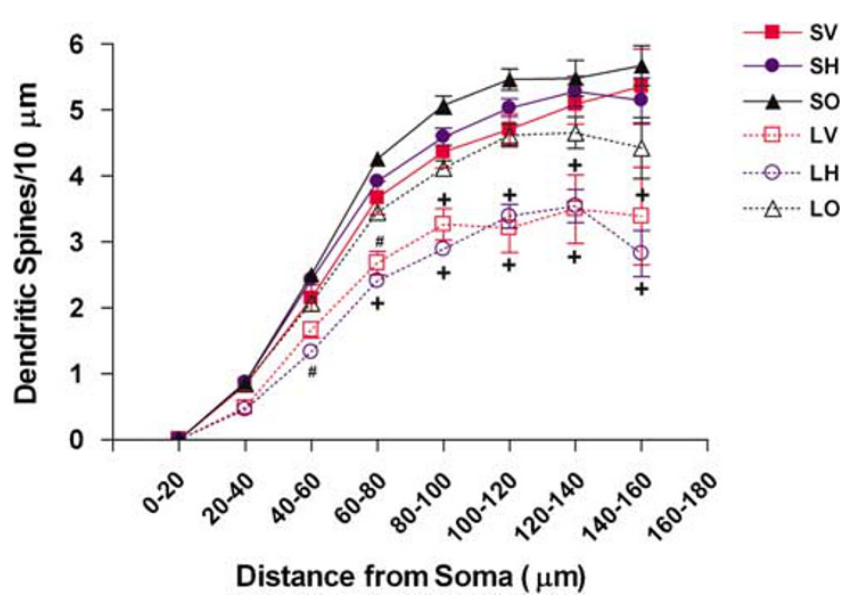

Figure 4 Dendritic spine density as a function of distance from the soma. Spine density in lesioned rats treated with vehicle (LV) was decreased relative to sham-lesioned vehicle-treated (SV) animals starting at $60 \mu \mathrm{m}$ distal to the soma. Olanzapine administered to lesioned rats (LO) reversed spine density to values comparable to those seen in sham-lesioned vehicleinjected (SV) and sham-lesioned olanzapine-treated (SO) rats, while haloperidol treatment of lesioned rats $(\mathrm{LH})$ had no such effect. ${ }^{+} p \leqslant 0.0$ I and ${ }^{\#} p \leqslant 0.05$ relative to sham-lesioned vehicle-treated rats at the same distance on the dendritic arbor from the soma.

not haloperido1 (Figures 2, 3 and 6). Neither APD had any effect on dendritic parameters in sham-lesioned rats.

The Sholl analysis, in which the number of intersections made by dendrites at progressively more distal circles surrounding the soma is calculated, revealed significant treatment $\left(\mathrm{F}_{5,177}=15.7, \quad p<0.0001\right)$ and distance $\left(\mathrm{F}_{5,177}=110.2, p<0.0001\right)$ effects on dendritic intersections, with no significant interaction (see Figures 5 and 6). As was seen with other dendritic parameters, olanzapine reversed the decrease in dendritic intersections induced by cortical dopamine depletion . Finally, the VTA lesions resulted in a significant decrease in spine density on apical dendritic segments located $80-100 \mu \mathrm{m}$ distal to the soma $\left(\mathrm{F}_{5,29}=5.88\right.$, $p<0.001$ ), with olanzapine but not haloperidol reversing the lesion-induced decrease. Neither olanzapine or haloperidol treatment of sham-lesioned animals caused any significant change in apical spine density.

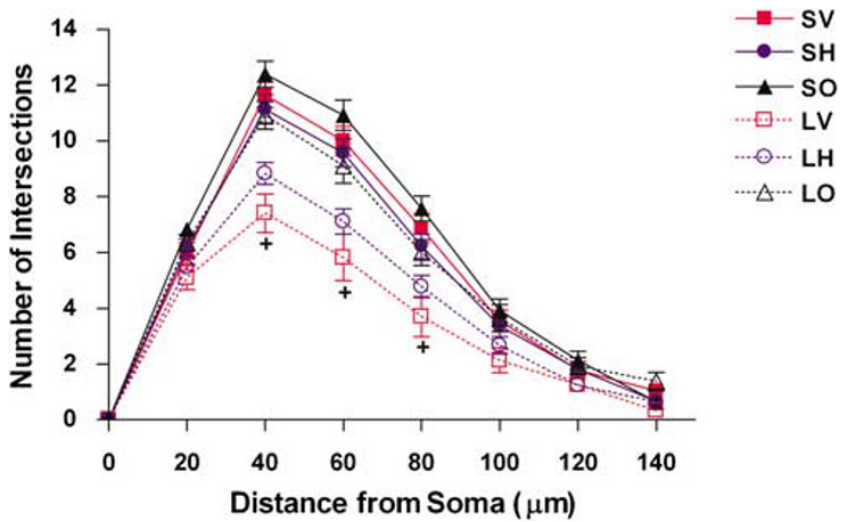

Figure 5 Sholl analysis of dendritic intersections at progressive $20 \mu \mathrm{m}$ distances from the soma. Animals with 6-OHDA lesions of the VTA treated with vehicle (LV) showed fewer intersections than sham-lesioned vehicle-treated animals (SV) at 40,60 and $80 \mu \mathrm{m}$ distal to the soma. Olanzapine treatment of lesioned rats (LO) reversed the decrease in dendritic branching. Lesioned animals treated with haloperidol $(\mathrm{LH})$ also tended to show fewer intersections relative to SV and $\mathrm{SH}$ animals, but these effects did not reach statistical significance. ${ }^{+} p \leqslant 0.05$.

\section{DISCUSSION}

\section{Dendritic Reorganization of PFC Pyramidal Cells}

There has been a surge of interest in uncovering the mechanisms that govern dendritic structure in vivo, with a particular emphasis on cortical neurons. Recent reports indicate that both acute and chronic stress cause dystrophic changes in the dendrites of PFC pyramidal cells, including decreases in apical dendritic length and branching of layer II/III PCs, but no changes in the structure of the basal dendritic tree (Seib and Wellman, 2003; Radley et al, 2004, 2005; Brown et al, 2005; Izquierdo et al, 2006; Murmu et al, 2006). Consistent with the stress-induced decrease in apical dendritic length and branching, chronic corticosterone treatment decreases apical dendritic length (Cerqueira et al, 2006).

Pharmacological interventions have also been shown to cause changes in PFC neuronal structure. Chronic phencyclidine treatment results in a decreased number of synapses on spines in superficial layer neurons of the primate PFC 

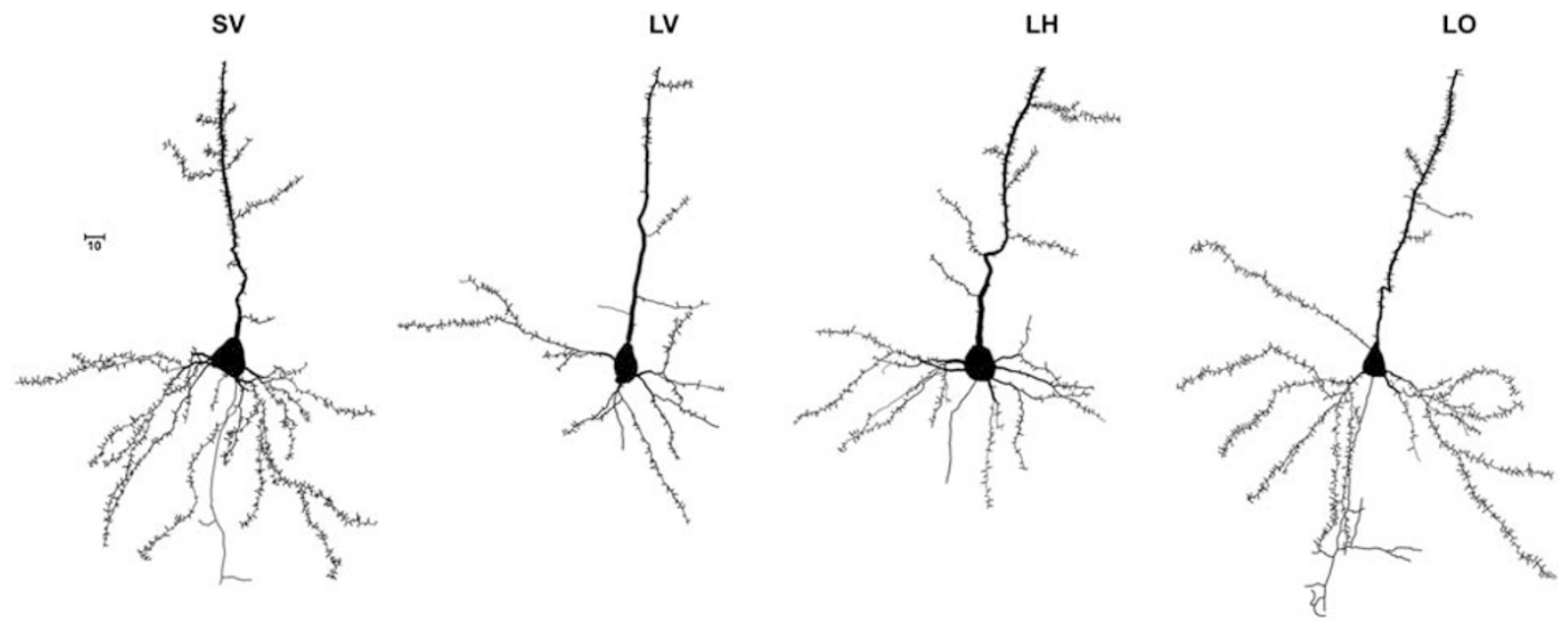

Figure 6 Reconstructions of representative superficial layer $V$ pyramidal cells in sham-lesioned vehicle-treated (SV) animals and 6-OHDA-lesioned rats treated with vehicle (LV), haloperidol (LH) or olanzapine (LO). A marked decrease in the length and complexity of the basal dendritic arbor in the PC of a vehicle-treated lesioned animal can be seen, and one can appreciate a reduction in dendritic spines. Treatment of lesioned animals with haloperidol did not result in any substantial increase in basal dendritic length and branching, but the basal dendrites in a PC from a lesioned animal treated with olanzapine grossly appear to be longer and more complex.

(Hajszan et al, 2006). Morphine administration, both experimenter- and self-administered, has yielded somewhat different data, with one group reporting a decrease in dendritic spine density in layer $\mathrm{V}$ neurons of the PFC (Robinson et al, 2002) and another group observing an increase in spine number and dendritic length but a decrease in branching complexity of layer II/III PCs (Ballesteros-Yanez et al, 2007). It is not clear if differences across the two studies reflect a focus on superficial $v s$ deep layer PCs, or if the different strains of rats used are important. Increases in both layer III and V PFC pyramidal cell apical dendritic length and spine density are seen in response to chronic psychostimulant administration (Robinson and Kolb, 1997, 1999).

Differences in the afferents innervating and regulating the apical and basal dendrites suggest that various treatments may differentially or coordinately affect the apical and basal dendrites. We found that VTA lesions that disrupt the dopamine innervation of the PFC caused decreases in spine density and dendritic length of the basal dendrites of layer V PCs. We focused on layer V but not II/III PCs because the dopamine innervation of the rat PFC is most dense in the deep cortical layers but very sparse in layers II/III (Kalsbeek et al, 1988).

\section{Dopamine-dependent Remodeling of Dendritic Morphology}

The lesion-induced changes in dendrites that we observed were very similar in rats killed 3 weeks (experiment 1 ) and 6 weeks (experiment 2) after the lesions. The various dendritic parameters in the control animals in the two experiments were quite similar, and the magnitude of the lesion-induced changes in dendritic parameters in the two experiments were comparable. The only difference was that we observed a significant effect on apical spine density in VTA-lesioned vehicle-treated rats in the second experiment, but in the first experiment there was a non-significant $(p=0.055)$ trend toward a decrease. As noted earlier, we were unable to reconstruct the full apical dendritic tree of layer $\mathrm{V}$ cells for technical reasons, and therefore unable to determine if the difference in spine density is present along the entire apical dendrite and if apical dendritic length is changed.

Dystrophic dendritic changes similar to those that we observed in pyramidal cells have also been reported in striatal medium spiny neurons in response to experimental dopamine denervation and in postmortem samples from Parkinson's disease patients (Ingham et al, 1989; Stephens et al, 2005; Zaja-Milatovic et al, 2005; Day et al, 2006). A recent study (Solis et al, 2007) reported that 6-OHDA injections of the substantia nigra resulted in a decrease in spine density but not dendritic length in layer V PCs of what appears to be the medial precentral (shoulder) cortex, dorsal to the prelimbic cortex that we analyzed. A recent study of neonatal rats that received intraventricular injections of 6-OHDA, which caused a significant decline in PFC dopamine but not norepinephrine concentrations, did not observe any changes in the dendrites of layer V PCs (Sherren and Pappas, 2005). It will be interesting to determine if compensatory mechanisms that prevent spine loss in the face of cortical dopamine depletion are present in neonatal animals.

Our data that PFC dopamine deafferentation decreases dendritic length and spine density complements earlier studies on psychostimulants, which found that amphetamine and cocaine (which increase both extracellular dopamine and norepinephrine levels) cause an increase in spine density (Robinson et al, 2001, 2002). We did not observe a significant decrease in PFC norepinephrine concentrations in VTA-lesioned rats, suggesting that the loss of cortical dopamine is the proximate cause of the dendritic changes. This suggestion is consistent with recent data indicating dendritic changes in PFC PCs of $D_{1}$ knockout mice (Stanwood et al, 2005).

The similar dendritic responses of PFC pyramidal cells and striatal medium spiny neurons to dopamine denervation may reflect a common triadic synaptic organization 
that involves glutamatergic and dopaminergic axons and the dendrites of their postsynaptic targets in both the PFC and striatum (Freund et al, 1984; Sesack et al, 2003). This structural arrangement suggests that the loss of dopamine signaling results in an inability of the postsynaptic cell to gate increased excitatory drive, culminating in dendritic spine loss (Cepeda et al, 2001). A large body of data has revealed that activity-dependent signaling through glutamate receptors is a key determinant of spine density and morphology (Segal and Andersen, 2000; Carlisle and Kennedy, 2005).

It is interesting to note that dopamine denervation of the PFC resulted in changes in dendritic spine density and length that are greater in magnitude than those changes seen in striatal neurons after dopamine denervation. As note above, PFC PCs and striatal MSNs share a common synaptic architecture involving dopamine and an excitatory input converging onto a spine, although the frequency of such synaptic triads is lower in the PFC (Sesack et al, 2003). It is possible that other factors elaborated from dopamine neurons, including neurotensin and brain-derived neurotrophic factor, may contribute to the somewhat larger effect of dopamine denervation seen on PFC PC dendrites. However, we have recently found changes in prelimbic cortex layer $\mathrm{V}$ pyramidal cell dendrites in D1 receptor null mutant mice that fully recapitulate the dystrophic changes in PC dendrites seen after dopamine denervation, suggesting that the major contributor the changes in dendrites is the loss of dopamine signaling (Wang et al, 2005). More likely is the fact that volume transmission appears to play a much greater role in dopamine function in the PFC, owing to the paucity of dopamine transporter expression on dopamine axons innervating the PFC (Sesack et al, 1998), which would render dopamine released under normal conditions able to influence a greater number of dendrites.

\section{Mechanism of Olanzapine Reversal of Dopamine Denervation-Induced Dendritic Changes}

We found that treatment with an atypical but not a typical APD reversed dopamine denervation-induced changes in dendrites. Atypical APDs, including olanzapine, have broad receptor affinities (Bymaster et al, 1997; Arnt and Skarsfeldt, 1998), while haloperidol is primarily a $\mathrm{D}_{2}$ receptor antagonist in vivo (Arnt and Skarsfeldt, 1998). Benes et al, 1985 noted that long-term (16 week) haloperidol treatment resulted in a loss of PFC axon terminals with asymmetric synapses onto layer VI neurons, speculating that this was due to resorbed spiny processes, but did not directly measure spine density. We counted spines directly and found that haloperidol treatment of sham-lesioned rats for 3 weeks did not alter dendritic spine density, suggesting that either the $D_{2}$ receptor is not involved in dendritic remodeling of PFC neurons or that haloperidol treatment must be of very long duration. As noted above, because dystrophic changes are seen in PFC PC dendrites in $D_{1}$ knockout mice (Stanwood et al, 2005; Wang et al, 2005), we suggest that a loss of dopamine signaling through the $D_{1}$ but not $\mathrm{D}_{2}$ receptor may be responsible for dopamine depletioninduced changes in PFC PC dendrites. The mechanism through which olanzapine reverses the dendritic changes induced by VTA lesions is not clear, but may reflect the ability of atypical APDs to increase PFC dopamine release - despite the fact that the dopamine innervation of the cortex was lesioned. Acute and chronic treatments with atypical APDs such as olanzapine increase extracellular levels of dopamine in the PFC, while typical APDs such as haloperidol do not (Youngren et al, 1994; Li et al, 1998). The ability of atypical APDs to increase cortical dopamine levels has been attributed in part to their antagonism of $\alpha_{2}$ autoreceptors, leading to activation of noradrenergic neurons and the subsequent release of dopamine from cortical noradrenergic axons (Li et al, 1998; Devoto et al, 2003). When the firing rate of noradrenergic neurons is increased, as occurs with olanzapine (Dawe et al, 2001), dopamine- $\beta$-hydroxylase rather than tyrosine hydroxylase becomes the rate-limiting (Scatton et al, 1983). Because the $\mathrm{NE}$ synthetic enzyme dopamine- $\beta$-hydroxylase is localized to vesicles, dopamine accumulated by the vesicle is not fully converted to $\mathrm{NE}$ in activated noradrenergic neurons, and is released from the terminals of these cells in an impulsedependent manner. The release of dopamine from noradrenergic axons offers a mechanism explaining how an atypical APD may increase extracellular PFC dopamine levels in the face of cortical dopamine depletion. Clearly, future work will be required to untangle the degree to which various factors contribute to the observed action of olanzapine.

The ability of APDs to reverse established changes in the dendrites of PCs after dopamine denervation is consistent with the dynamic nature of dendritic spines. Interestingly, the changes in dendrites of PFC neurons that are seen in response to chronic stress resolve upon discontinuation of the stressor (Radley et al, 2005), suggesting that dystrophic changes in dendrites may be reversed with appropriate interventions in some cases. However, studies on the effects of psychostimulants and environmental enrichment in the parietal cortex by Kolb et al (2003) indicate that in other cases it is not possible to reverse established dendritic spine loss.

\section{Relation to the Pathology of Schizophrenia}

Dendritic changes in frontal cortical pyramidal cells are among the most replicated of findings in postmortem studies of schizophrenia (Garey et al, 1998; Glantz and Lewis, 2000; Kalus et al, 2000; Broadbelt et al, 2002; Black et al, 2004; Kolluri et al, 2005). A large body of data is consistent with a decrease in dopamine tone in the PFC in schizophrenia (Weinberger et al, 1988; Davis et al, 1991; Deutch, 1992; Goldman-Rakic and Selemon, 1997; Knable and Weinberger, 1997; Goldman-Rakic et al, 2004; Gibbs and D'Esposito, 2005) and Akil et al (1999) reported that the density of the dopamine innervation of the dorsolateral PFC is decreased in schizophrenia. We do not advance VTA 6-OHDA lesions as a model of schizophrenia. However, this approach offers a means of testing one specific aspect of the pathology of schizophrenia, the dendritic changes in the prefrontal cortices. Our observation that lesions of the PFC dopamine innervation cause dendritic changes similar to those seen in schizophrenia suggests that the proximate cause of the dendritic spine loss of PFC cells in schizophrenia may be impaired dopaminergic transmission.

Most postmortem studies of PC dendrites in schizophrenia have focused on layer III neurons, which in humans receives a dense dopamine innervation. We examined cells 
in layer $\mathrm{V}$, which in the rat is targeted by dopamine axons. Of the two postmortem studies that evaluated layer V PCs in schizophrenia, one reported a decrease in dendritic branching (Black et al, 2004) but the other found no change in dendritic parameters (Kolluri et al, 2005). The former study examined anterior orbitofrontal cortex, while the latter focused on the dorsolateral prefrontal cortex. We observed changes in both dendritic length and spine density in the prelimbic cortex of the rat. Because the medial PFC of the rat evolves into several spatially segregated frontal cortical regions with different cytoarchitectonic characteristics in humans, the prelimbic cortex of the medial PFC of the rat is probably not homologous to a single primate prefrontal cortical region (Uylings et al, 2003).

Olanzapine, but not haloperidol, has been reported to prevent gradual cortical volume loss over the first 2 years of the active illness (Lieberman et al, 2005b). It remains to be determined if olanzapine treatment will reverse established structural changes in patients with chronic illness. In our study, we examined the effects of PFC dopamine depletion in young adult animals, but age-related changes in dendritic structure, as have been reported in primates (Duan et al, 2003), may limit the ability of treatments to reverse or attenuate dendritic changes. Additional studies will be required to define the degree to which structural changes in PC dendrites can be reversed by treatments commencing long after dendritic changes have been established.

We can draw clear parallels between the changes in pyramidal cell dendrites seen in animals with cortical dopamine depletion and the pathological changes observed in the PFC in schizophrenia. Less clear, however, is the relationship between the ability of an atypical antipsychotic drug to reverse dopamine depletion-induced changes in dendrites and clinical response to the atypical APD. Although a large body of literature has reported that atypical APDs are superior to typical agents in the treatment of schizophrenia, including response in cognitive domains, more recently a recent large multicenter study using time to discontinue treatment for any reason as an end point found several atypical APDs to be comparable to a single reference typical APD (Lieberman et al, 2005a). More detailed analyses of the data from this study, including a recent one on cognitive responses to APDs, similarly found a lack of superiority of atypical over typical APDs (Keefe et al, 2007). Even in the first episode study of Lieberman et al (2005b) that found less cortical volume in patients treated with olanzapine and haloperidol, overall therapeutic response was comparable in the olanzapine- and haloperidoltreated groups (Green et al, 2006), although some secondary measures (such as remission rates, likelihood to discontinue treatment, and depression ratings) were better in patients treated with the atypical APD. The ability to tie the dendritic changes to specific therapeutic responses, ranging from negative symptoms to various cognitive domains, will require expanded clinicopathological correlations in largescale prospective studies.

\section{Conclusions}

Lesions that disrupt the dopamine innervation of the PFC resulted in dystrophic changes in the dendrites of layer $\mathrm{V}$ pyramidal cells. These changes are similar to those observed in postmortem studies of schizophrenia, in which the dopamine innervation of the PFC appears to be compromised. Moreover, our observations on the effects of APDs are consistent with emerging clinical data suggesting that the structural changes in schizophrenia can be attenuated by atypical APDs (Lieberman et al, 2005b).

We have addressed a pathological consequence of PFC dopamine denervation, but not the normal physiological functions of dopamine in determining or maintaining PFC dendritic structure. Changes in dopamine signaling alter the tuning of PFC neurons during working memory tasks (Goldman-Rakic, 1999; Rao et al, 2000; Meyer-Lindenberg et al, 2005). Interestingly, VTA stimulation paired with presentation of a tone increases the size of the cortical field that responds to the stimulus and increases selectivity of the response to the tone (Bao et al, 2001). Such changes in selectivity may be due to increases in the dendritic architecture of cortical pyramidal cells. Conversely, dopamine depletion-induced dystrophic changes in dendrites of pyramidal cells in association cortices may be associated with decreased tuning and contribute to cognitive deficits in schizophrenia.

\section{ACKNOWLEDGEMENTS}

We appreciate the assistance of Tamara Geraci Altman in figure preparation, and the helpful comments of Brian Mathur, Michael Bubser and Diana Neely. Deqiang Jing worked on pilot experiments. This work was supported in part by RO1 MH077298, PO1 NS044282, and an investigator-initiated grant from Eli Lilly.

\section{DISCLOSURE/CONFLICT OF INTEREST}

The author(s) declare that, except for income received from my primary employer, no financial support or compensation has been received from any individual or corporate entity over the past 3 years for research or professional service and there are no personal financial holdings that could be perceived as constituting a potential conflict of interest, except for the following: part of this work was supported by an investigator-initiated grant from Eli Lilly \& Co. AYD is a consultant to Eli Lilly. In addition, AYD derives support from the NIH and National Parkinson Foundation.

\section{REFERENCES}

Akil M, Pierri JN, Whitehead RE, Edgar CL, Mohila C, Sampson AR et al (1999). Lamina-specific alterations in the dopamine innervation of the prefrontal cortex in schizophrenic subjects. Am J Psychiatry 156: 1580-1589.

Antonova E, Sharma T, Morris R, Kumari V (2004). The relationship between brain structure and neurocognition in schizophrenia: a selective review. Schizophr Res 70: 117-145.

Arnsten AF (2004). Adrenergic targets for the treatment of cognitive deficits in schizophrenia. Psychopharmacology (Berl) 174: 25-31.

Arnt J, Skarsfeldt T (1998). Do novel antipsychotics have similar pharmacological characteristics? A review of the evidence. Neuropsychopharmacology 18: 63-101. 
Ballesteros-Yanez I, Ambrosio E, Benavides-Piccione R, Perez J, Torres I, Miguens $M$ et al (2007). The effects of morphine selfadministration on cortical pyramidal cell structure in addictionprone lewis rats. Cereb Cortex 17: 238-249.

Bao S, Chan VT, Merzenich MM (2001). Cortical remodelling induced by activity of ventral tegmental dopamine neurons. Nature 412: 79-83.

Benes FM, Paskevich PA, Davidson J, Domesick VB (1985). The effects of haloperidol on synaptic patterns in the rat striatum. Brain Res 329: 265-273.

Bilder RM, Goldman RS, Volavka J, Czobor P, Hoptman M, Sheitman B et al (2002). Neurocognitive effects of clozapine, olanzapine, risperidone, and haloperidol in patients with chronic schizophrenia or schizoaffective disorder. Am J Psychiatry 159: 1018-1028.

Black JE, Kodish IM, Grossman AW, Klintsova AY, Orlovskaya D, Vostrikov V et al (2004). Pathology of layer V pyramidal neurons in the prefrontal cortex of patients with schizophrenia. Am J Psychiatry 161: 742-744.

Blanpied TA, Ehlers MD (2004). Microanatomy of dendritic spines: emerging principles of synaptic pathology in psychiatric and neurological disease. Biol Psychiatry 55: 1121-1127.

Broadbelt K, Byne W, Jones LB (2002). Evidence for a decrease in basilar dendrites of pyramidal cells in schizophrenic medial prefrontal cortex. Schizophr Res 58: 75-81.

Brown SM, Henning S, Wellman CL (2005). Mild, short-term stress alters dendritic morphology in rat medial prefrontal cortex. Cereb Cortex 15: 1714-1722.

Bymaster FP, Rasmussen K, Calligaro DO, Nelson DL, DeLapp NW, Wong DT et al (1997). In vitro and in vivo biochemistry of olanzapine: a novel, atypical antipsychotic drug. J Clin Psychiatry 58(Suppl 10): 28-36.

Cahn W, Hulshoff Pol HE, Lems EB, van Haren NE, Schnack HG, van der Linden JA et al (2002). Brain volume changes in firstepisode schizophrenia: a 1-year follow-up study. Arch Gen Psychiatry 59: 1002-1010.

Carlisle HJ, Kennedy MB (2005). Spine architecture and synaptic plasticity. Trends Neurosci 28: 182-187.

Cepeda C, Hurst RS, Altemus KL, Flores-Hernandez J, Calvert CR, Jokel ES et al (2001). Facilitated glutamatergic transmission in the striatum of D2 dopamine receptor-deficient mice. J Neurophysiol 85: 659-670.

Cerqueira JJ, Taipa R, Uylings HB, Almeida OF, Sousa N (2006). Specific configuration of dendritic degeneration in pyramidal neurons of the medial prefrontal cortex induced by differing corticosteroid regimens. Cereb Cortex (doi:10.1093/cercor/ bhii08).

Crick F (1982). Do dendritic spines twitch? Trends Neurosci 5: 44-46.

Dalley JW, Cardinal RN, Robbins TW (2004). Prefrontal executive and cognitive functions in rodents: neural and neurochemical substrates. Neurosci Biobehav Rev 28: 771-784.

Davis KL, Kahn RS, Ko G, Davidson M (1991). Dopamine in schizophrenia: a review and reconceptualization. Am J Psychiatry 148: 1474-1486.

Dawe GS, Huff KD, Vandergriff JL, Sharp T, O’Neill MJ, Rasmussen $\mathrm{K}$ (2001). Olanzapine activates the rat locus coeruleus: in vivo electrophysiology and c-Fos immunoreactivity. Biol Psychiatry 50: $510-520$.

Day M, Wang Z, Ding J, An X, Ingham CA, Shering AF et al (2006). Selective elimination of glutamatergic synapses on striatopallidal neurons in Parkinson disease models. Nat Neurosci 9: 251-259.

Deutch AY (1992). The regulation of subcortical dopamine systems by the prefrontal cortex: interactions of central dopamine systems and the pathogenesis of schizophrenia. J Neural Transm Suppl 36: 61-89.

Deutch AY, Cameron DS (1992). Pharmacological characterization of dopamine systems in the nucleus accumbens core and shell. Neuroscience 46: 49-56.
Deutch AY, Clark WA, Roth RH (1990). Prefrontal cortical dopamine depletion enhances the responsiveness of mesolimbic dopamine neurons to stress. Brain Res 521: 311-315.

Deutch AY, Tam SY, Roth RH (1985). Footshock and conditioned stress increase 3,4-dihydroxyphenylacetic acid (DOPAC) in the ventral tegmental area but not substantia nigra. Brain Res 333: 143-146.

Devoto P, Flore G, Vacca G, Pira L, Arca A, Casu MA et al (2003). Co-release of noradrenaline and dopamine from noradrenergic neurons in the cerebral cortex induced by clozapine, the prototype atypical antipsychotic. Psychopharmacology (Berl) 167: 79-84.

Duan H, Wearne SL, Rocher AB, Macedo A, Morrison JH, Hof PR (2003). Age-related dendritic and spine changes in corticocortically projecting neurons in macaque monkeys. Cereb Cortex 13: 950-961.

Fiala JC, Spacek J, Harris KM (2002). Dendritic spine pathology: cause or consequence of neurological disorders? Brain Res Brain Res Rev 39: 29-54.

Freund TF, Powell JF, Smith AD (1984). Tyrosine hydroxylaseimmunoreactive boutons in synaptic contact with identified striatonigral neurons, with particular reference to dendritic spines. Neuroscience 13: 1189-1215.

Garey LJ, Ong WY, Patel TS, Kanani M, Davis A, Mortimer AM et al (1998). Reduced dendritic spine density on cerebral cortical pyramidal neurons in schizophrenia. J Neurol Neurosurg Psychiatry 65: 446-453.

Gibbs SE, D'Esposito M (2005). A functional MRI study of the effects of bromocriptine, a dopamine receptor agonist, on component processes of working memory. Psychopharmacology (Berl) 180: 644-653.

Glantz LA, Lewis DA (2000). Decreased dendritic spine density on prefrontal cortical pyramidal neurons in schizophrenia. Arch Gen Psychiatry 57: 65-73.

Goldman-Rakic PS (1996). Regional and cellular fractionation of working memory. Proc Natl Acad Sci USA 93: 13473-13480.

Goldman-Rakic PS (1999). The 'psychic' neuron of the cerebral cortex. Ann NY Acad Sci 868: 13-26.

Goldman-Rakic PS, Castner SA, Svensson TH, Siever LJ, Williams GV (2004). Targeting the dopamine D1 receptor in schizophrenia: insights for cognitive dysfunction. Psychopharmacology (Berl) 174: 3-16.

Goldman-Rakic PS, Selemon LD (1997). Functional and anatomical aspects of prefrontal pathology in schizophrenia. Schizophr Bull 23: 437-458.

Green AI, Lieberman JA, Hamer RM, Glick ID, Gur RE, Kahn RS et al (2006). Olanzapine and haloperidol in first episode psychosis: two-year data. Schizophr Res 86: 234-243.

Gur RE, Cowell PE, Latshaw A, Turetsky BI, Grossman RI, Arnold SE et al (2000). Reduced dorsal and orbital prefrontal gray matter volumes in schizophrenia. Arch Gen Psychiatry 57: 761-768.

Hajszan T, Leranth C, Roth RH (2006). Subchronic phencyclidine treatment decreases the number of dendritic spine synapses in the rat prefrontal cortex. Biol Psychiatry 60: 639-644.

Halim ND, Weickert CS, McClintock BW, Hyde TM, Weinberger DR, Kleinman JE et al (2003). Presynaptic proteins in the prefrontal cortex of patients with schizophrenia and rats with abnormal prefrontal development. Mol Psychiatry 8: 797-810.

Hao J, Rapp PR, Leffler AE, Leffler SR, Janssen WG, Lou W et al (2006). Estrogen alters spine number and morphology in prefrontal cortex of aged female rhesus monkeys. J Neurosci 26: 2571-2578.

Harrison PJ (1999). The neuropathology of schizophrenia. A critical review of the data and their interpretation. Brain 122(Part 4): 593-624.

Hill JJ, Hashimoto T, Lewis DA (2006). Molecular mechanisms contributing to dendritic spine alterations in the prefrontal cortex of subjects with schizophrenia. Mol Psychiat 11: 557-566. 
Hof PR, Haroutunian V, Friedrich Jr VL, Byne W, Buitron C, Perl DP et al (2003). Loss and altered spatial distribution of oligodendrocytes in the superior frontal gyrus in schizophrenia. Biol Psychiatry 53: 1075-1085.

Ingham CA, Hood SH, Arbuthnott GW (1989). Spine density on neostriatal neurones changes with 6-hydroxydopamine lesions and with age. Brain Res 503: 334-338.

Izquierdo A, Wellman CL, Holmes A (2006). Brief uncontrollable stress causes dendritic retraction in infralimbic cortex and resistance to fear extinction in mice. J Neurosci 26: 5733-5738.

Kalsbeek A, Voorn P, Buijs RM, Pool CW, Uylings HB (1988). Development of the dopaminergic innervation in the prefrontal cortex of the rat. J Comp Neurol 269: 58-72.

Kalus P, Muller TJ, Zuschratter W, Senitz D (2000). The dendritic architecture of prefrontal pyramidal neurons in schizophrenic patients. Neuroreport 11: 3621-3625.

Keefe RS, Bilder RM, Davis SM, Harvey PD, Palmer BW, Gold JM et al (2007). Neurocognitive effects of antipsychotic medications in patients with chronic schizophrenia in the CATIE Trial. Arch Gen Psychiatry 64: 633-647.

Keefe RS, Seidman LJ, Christensen BK, Hamer RM, Sharma T, Sitskoorn MM et al (2004). Comparative effect of atypical and conventional antipsychotic drugs on neurocognition in first-episode psychosis: a randomized, double-blind trial of olanzapine versus low doses of haloperidol. Am J Psychiatry 161: 985-995.

Knable MB, Weinberger DR (1997). Dopamine, the prefrontal cortex and schizophrenia. J Psychopharmacol 11: 123-131.

Kolb B, Gorny G, Li Y, Samaha AN, Robinson TE (2003). Amphetamine or cocaine limits the ability of later experience to promote structural plasticity in the neocortex and nucleus accumbens. Proc Natl Acad Sci USA 100: 10523-10528.

Kolluri N, Sun Z, Sampson AR, Lewis DA (2005). Lamina-specific reductions in dendritic spine density in the prefrontal cortex of subjects with schizophrenia. Am J Psychiatry 162: 1200-1202.

Krettek JE, Price JL (1977). The cortical projections of the mediodorsal nucleus and adjacent thalamic nuclei in the rat. J Comp Neurol 171: 157-191.

Lewis DA, Lieberman JA (2000). Catching up on schizophrenia: natural history and neurobiology. Neuron 28: 325-334.

Li XM, Perry KW, Wong DT, Bymaster FP (1998). Olanzapine increases in vivo dopamine and norepinephrine release in rat prefrontal cortex, nucleus accumbens and striatum. Psychopharmacology (Berl) 136: 153-161.

Lieberman JA, Stroup TS, McEvoy JP, Swartz MS, Rosenheck RA, Perkins DO et al (2005a). Effectiveness of antipsychotic drugs in patients with chronic schizophrenia. $N$ Engl J Med 353: 1209-1223.

Lieberman JA, Tollefson GD, Charles C, Zipursky R, Sharma T, Kahn RS et al (2005b). Antipsychotic drug effects on brain morphology in first-episode psychosis. Arch Gen Psychiatry 62: 361-370.

Meltzer HY, Park S, Kessler R (1999). Cognition, schizophrenia, and the atypical antipsychotic drugs. Proc Natl Acad Sci USA 96: 13591-13593.

Meyer-Lindenberg A, Kohn PD, Kolachana B, Kippenhan S, McInerney-Leo A, Nussbaum R et al (2005). Midbrain dopamine and prefrontal function in humans: interaction and modulation by COMT genotype. Nat Neurosci 8: 594-596.

Mirnics K, Middleton FA, Lewis DA, Levitt P (2001). Analysis of complex brain disorders with gene expression microarrays: schizophrenia as a disease of the synapse. Trends Neurosci 24: 479-486.

Murmu MS, Salomon S, Biala Y, Weinstock M, Braun K, Bock J (2006). Changes of spine density and dendritic complexity in the prefrontal cortex in offspring of mothers exposed to stress during pregnancy. Eur J Neurosci 24: 1477-1487.
Park S, Holzman PS (1992). Schizophrenics show spatial working memory deficits. Arch Gen Psychiatry 49: 975-982.

Perez-Costas E, Guidetti P, Leeley JJ, Melendez-Ferro M, Roberts RC (2005). Neuroleptic and animals models: feasibility of oral treatment monitored by plasma levels and receptor occupancy assays. Soc Neurosci (Abstr 914.18).

Pierri JN, Volk CL, Auh S, Sampson A, Lewis DA (2003). Somal size of prefrontal cortical pyramidal neurons in schizophrenia: differential effects across neuronal subpopulations. Biol Psychiatry 54: 111-120.

Radley JJ, Rocher AB, Janssen WG, Hof PR, McEwen BS, Morrison $\mathrm{JH}$ (2005). Reversibility of apical dendritic retraction in the rat medial prefrontal cortex following repeated stress. Exp Neurol 196: 199-203.

Radley JJ, Sisti HM, Hao J, Rocher AB, McCall T, Hof PR et al (2004). Chronic behavioral stress induces apical dendritic reorganization in pyramidal neurons of the medial prefrontal cortex. Neuroscience 125: 1-6.

Ragozzino ME, Detrick S, Kesner RP (2002). The effects of prelimbic and infralimbic lesions on working memory for visual objects in rats. Neurobiol Learn Mem 77: 29-43.

Rao SG, Williams GV, Goldman-Rakic PS (2000). Destruction and creation of spatial tuning by disinhibition: GABA(A) blockade of prefrontal cortical neurons engaged by working memory. J Neurosci 20: 485-494.

Robinson TE, Gorny G, Mitton E, Kolb B (2001). Cocaine selfadministration alters the morphology of dendrites and dendritic spines in the nucleus accumbens and neocortex. Synapse 39: 257-266.

Robinson TE, Gorny G, Savage VR, Kolb B (2002). Widespread but regionally specific effects of experimenter- versus selfadministered morphine on dendritic spines in the nucleus accumbens, hippocampus, and neocortex of adult rats. Synapse 46: $271-279$.

Robinson TE, Kolb B (1997). Persistent structural modifications in nucleus accumbens and prefrontal cortex neurons produced by previous experience with amphetamine. J Neurosci 17: 8491-8497.

Robinson TE, Kolb B (1999). Alterations in the morphology of dendrites and dendritic spines in the nucleus accumbens and prefrontal cortex following repeated treatment with amphetamine or cocaine. Eur J Neurosci 11: 1598-1604.

Scatton B, Javoy-Agid F, Rouquier L, Dubois B, Agid Y (1983). Reduction of cortical dopamine, noradrenaline, serotonin and their metabolites in Parkinson's disease. Brain Res 275: 321-328.

Segal M, Andersen P (2000). Dendritic spines shaped by synaptic activity. Curr Opin Neurobiol 10: 582-586.

Seib LM, Wellman CL (2003). Daily injections alter spine density in rat medial prefrontal cortex. Neurosci Lett 337: 29-32.

Selemon LD, Goldman-Rakic PS (1999). The reduced neuropil hypothesis: a circuit based model of schizophrenia. Biol Psychiatry 45: 17-25.

Selemon LD, Lidow MS, Goldman-Rakic PS (1999). Increased volume and glial density in primate prefrontal cortex associated with chronic antipsychotic drug exposure. Biol Psychiatry 46: 161-172.

Sesack SR, Carr DB, Omelchenko N, Pinto A (2003). Anatomical substrates for glutamate-dopamine interactions: evidence for specificity of connections and extrasynaptic actions. Ann NY Acad Sci 1003: 36-52.

Sesack SR, Hawrylak VA, Matus C, Guido MA, Levey AI (1998). Dopamine axon varicosities in the prelimbic division of the rat prefrontal cortex exhibit sparse immunoreactivity for the dopamine transporter. J Neurosci 18: 2697-2708.

Sherren N, Pappas BA (2005). Selective acetylcholine and dopamine lesions in neonatal rats produce distinct patterns of cortical dendritic atrophy in adulthood. Neuroscience 136: $445-456$ 
Solis O, Limón DI, Flores-Hernández J, Flores G (2007). Alterations in dendritic morphology of the prefrontal cortical and striatum neurons in the unilateral 6-OHDA-rat model of Parkinson's disease. Synapse 61: 450-458.

Stanwood GD, Parlaman JP, Levitt P (2005). Anatomical abnormalities in dopaminoceptive regions of the cerebral cortex of dopamine D1 receptor mutant mice. J Comp Neurol 487: 270-282.

Stephens B, Mueller AJ, Shering AF, Hood SH, Taggart P, Arbuthnott GW et al (2005). Evidence of a breakdown of corticostriatal connections in Parkinson's disease. Neuroscience 132: 741-754.

Terry AV, Gearhart DA, Mahadik SP, Warsi S, Davis LW, Waller JL (2005). Chronic exposure to typical or atypical antipsychotics in rodents: temporal effects on central $\alpha_{7}$ nicotinic acetylcholine receptors. Neurosci 136: 519-529.

Thune JJ, Uylings HB, Pakkenberg B (2001). No deficit in total number of neurons in the prefrontal cortex in schizophrenics. J Psychiatr Res 35: 15-21.

Uylings HB, Groenewegen HJ, Kolb B (2003). Do rats have a prefrontal cortex? Behav Brain Res 146: 3-17.

Van Eden CG, Hoorneman EM, Buijs RM, Matthijssen MA, Geffard M, Uylings HB (1987). Immunocytochemical localization of dopamine in the prefrontal cortex of the rat at the light and electron microscopical level. Neuroscience 22: 849-862.

Volavka J, Czobor P, Sheitman B, Lindenmayer JP, Citrome L, McEvoy JP et al (2002). Clozapine, olanzapine, risperidone, and haloperidol in the treatment of patients with chronic schizophrenia and schizoaffective disorder. Am J Psychiatry 159: 255-262.

Wang HD, Stanwood GD, Grandy DK, Deutch AY (2005). Dystrophic dendritic changes in prefrontal cortical pyramidal cells of dopamine $\mathrm{D}_{1}$ and $\mathrm{D}_{2}$ receptor knockout mice. Soc Neurosci Abstr 555: 12.

Weinberger DR, Berman KF, Illowsky BP (1988). Physiological dysfunction of dorsolateral prefrontal cortex in schizophrenia. III. A new cohort and evidence for a monoaminergic mechanism. Arch Gen Psychiatry 45: 609-615.

Youngren KD, Moghaddam B, Bunney BS, Roth RH (1994). Preferential activation of dopamine overflow in prefrontal cortex produced by chronic clozapine treatment. Neurosci Lett 165: $41-44$.

Zaja-Milatovic S, Milatovic D, Schantz AM, Zhang J, Montine KS, Samii A et al (2005). Dendritic degeneration in neostriatal medium spiny neurons in Parkinson disease. Neurology 64: 545-547. 